\title{
Chronic morbidity and reported disability among older persons from the India Human Development Survey
}

\author{
Mukesh C. Parmar ${ }^{1 *}$ (D) and Nandita Saikia ${ }^{1,2}$
}

\begin{abstract}
Background: The burden of disability and chronic morbidity among the elderly has been increasing substantially in India in recent years. Yet, the use of nationally representative data to investigate the relationship between chronic morbidity and reported disability in the country has been minimal. The objective of this study is twofold: i) to quantify the association between chronic morbidities and overall disabilities in the activities of daily living (ADLs) among elderly people in India, and ii) to understand how various chronic morbidities influence individual ADLs, specifically, walking, toileting and dressing.

Methods: We used data from the India Human Development Survey-II (IHDS-II) as a basis for this study. We computed the Katz Index of independence in ADL to examine the burden of disability among the elderly. Ordered logistic regression was carried out to examine the effect of chronic morbidities on: i) the disability index (where $0=$ no disability; $1=$ disability in 1 or $2 \mathrm{ADLs}$; and 2 = disability in $3 \mathrm{ADLs}$ ), and ii) disabilities in three ADLs in the population over-60 years of age in India.

Results: The percentage of people scoring lower Katz index (indicating severe and mild disability) in at least one of the three ADLs is very high in India (17.91\% for males and $26.21 \%$ for females). Irrespective of the type of ADL, the Katz score is lower in elderly females than in elderly males. Elderly people who are illiterate and belong to the poorest wealth quintile report lower Katz scores in ADL. Both bivariate and multivariate analyses confirm that all three types of chronic morbidities are positively and significantly associated with a disability condition in the ADLs. Yet, the effects of morbidities vary greatly according to the type of disability. For instance, while diabetes affect walking (OR: 2.56; 95\% Cl: 2.29-2.86), and toileting (OR: 2.63; 95\% Cl: 2.263.07), high blood pressure mainly affects walking (OR: 2.29, 95\% Cl: 2.09-2.5) and dressing disabilities (OR: 2. 13, 95\% Cl: 1.84-2.46).
\end{abstract}

Conclusions: Chronic morbidity is a decisive factor in old age disability. It is crucial to reduce chronic morbidity in a timely way to minimise the enormous associated burden of disability.

Keywords: Activities of daily living, ADL, Ageing, Disability, Morbidity, India Human Development Survey, IHDS, India, Katz index, Katz score

\footnotetext{
* Correspondence: mukesh.c.parmar@gmail.com

${ }^{1}$ Centre for the Study of Regional Development, School of Social Sciences,

Jawaharlal Nehru University, New Delhi, India

Full list of author information is available at the end of the article
}

(c) The Author(s). 2018 Open Access This article is distributed under the terms of the Creative Commons Attribution 4.0 International License (http://creativecommons.org/licenses/by/4.0/), which permits unrestricted use, distribution, and reproduction in any medium, provided you give appropriate credit to the original author(s) and the source, provide a link to the Creative Commons license, and indicate if changes were made. The Creative Commons Public Domain Dedication waiver (http://creativecommons.org/publicdomain/zero/1.0/) applies to the data made available in this article, unless otherwise stated. 


\section{Background}

According to the 2011 census, India is home to 27 million people with severe disabilities [1]. Around 5\% of the elderly population in the country are affected by some kind of disability [2], and the burden is predicted to increase substantially due to rising life expectancy and associated population aging. Despite this, studies addressing disability dynamics in India are limited.

Research in several other countries has shown that there is a strong association between chronic morbidities and disabilities [3, 4]. As severe morbidity disrupts normal daily activities, it reduces quality of life [5-8]. Some studies have found that arthritis $[4,9,10]$, cardiovascular disease, lung disorders, vision syndrome disabilities, and diabetes $[9,11]$ are common causes of physical disability. Depression and other major chronic diseases [12-14] can lead to mental disability. The interaction of various chronic diseases with physical disability [15] and the combined effects of two or more diseases [16] have also been conceptualised.

A literature survey on disability shows that the studies addressing disability in India mainly revolve around three principal issues. These are: i) the measurement of disability data in census and other surveys [17-19]; ii) differentials, determinants, and the impact of disability in general [2, 17, 20-23]; and iii) the pattern of disability regarding the health of older adults [19, 24-28]. In the first type of study, there is considerable debate on the actual prevalence of disability in India. For instance, the national sample survey (NSSO) and the national census are the two main data sources used in the measurement of disability in the country, but these differ in sample design, definition, and description of disability type [17-19]. In these studies, disability is measured in terms of disability prevalence, the disability index, and the age-standardized disability rate [1, 2, 29].

The second type of study focuses on the association between socioeconomic variables and disability. Females are found to be at higher risk of disability in old age than men $[1,2,9,30]$, but this gender gap has been decreasing over time [31]. Researchers have pointed out that age $[4,32]$ and education $[6,33,34]$ influence the disability status of the elderly.

The third type of study also deals with the interrelation between morbidity and disability [29, 35]. These studies from India show that diseases like arthritis, hypertension, diabetes, and other physiological disorders are all linked to disability in old age [35]. Several studies have addressed the effect of morbidities on the ADLs of elderly people $(60+)$, such as i) the effect of diabetes and other co-morbidities, like heart disease and hypertension on walking disability and other physical activities; ii) the effect of cataracts on vision syndrome disability [36]; and iii) mental disorders that cause hearing and speech impairments [37]. The states of Chandigarh and Haryana (2006) have revealed similar results, highlighting the strong association between morbidity and disability [29].

Previous studies conducted in India, however have two major limitations. First, they are based on primary sample survey, which restricts their study area to small geographical pockets of India and thus provide only a small sample size. Findings from these studies can therefore not be generalized to understand the nature and extent of the relationship between morbidities and disabilities for a large and heterogeneous country like India. Second, as all these studies have focused on the association between a specific type of disability and a set of morbidities, they have failed to provide a broad picture of the relative importance of morbidities for various types of disabilities among the elderly using the same study design. In the present study, we first examine the role of three important old-age morbidities on the overall disability status of elderly people in India using a recently available nationally representative survey. We then examine how each type of morbidity affects each type of disability in ADLs among the elderly in the country. The first part of the analysis helps to understand the relative importance of morbidities for the overall disability condition of the elderly, while the second part reveals the relative effect of each morbidity on each type of disability.

\section{Methods}

\section{Data description}

We used data from the second round of the India $\mathrm{Hu}$ man Development Survey (IHDS-II) [38], which was conducted in 2011-2012 and contains nationally representative longitudinal panel data. The survey covered about 42,152 households and 53,582 individuals across India. It was coordinated by the University of Maryland and the National Council of Applied Economic Research (NCAER), New Delhi. The survey covered a wide range of topics like health, employment, socioeconomic aspects, agriculture, economy, and education. A stratified random sampling technique was used for the survey. In the second round of the IHDS survey, information on morbidity and reported disability was recorded in the form of fifteen types of chronic morbidities and disabilities in seven types of ADL.

\section{Measurements \\ Dependent variables}

In this study, we define disability as "difficulty or inability" in the performance of ADLs by household members aged 60 and above.

In the present study, we considered disability in three ADLs for older persons in India, namely, walking, toileting and dressing. The exact question asked in the survey was: "Now, I am going to ask you about any physical 
difficulty that people above the age of 60 in this household may have. Does anyone in the household have a problem?" If the response is "yes," the next question is: "Can (name of the affected person) still do it with some trouble or is he/she unable to do it?" with options for three types of ADL: "i) walking $1 \mathrm{~km}$; ii) going to the toilet without help; iii) dressing without help". All these options have three responses, namely, "No difficulty", "Can do with difficulty" and "Unable to do it". The respondents to the above questions were women between the ages of 15 and 49 years matching the study criteria. We computed the Katz index of independence in ADL, referred to as the ' $\mathrm{Kz}$ score', to assign coding to these categories. Hence, a Kz score $=0$ signifies "Unable to do it", a $\mathrm{Kz}$ score = 1 signifies "Can do with difficulty", and a $\mathrm{Kz}$ score $=2$ signifies "No difficulty". The Katz Index of Independence in ADL, also called "Katz ADL" [39] is the standardised index for measuring the degree of functionality in ADL.

Similarly, Katz ADL is used to create a disability index to comprehend the effect of multiple disabilities in a sampled population. Here, we first categorized all types of disabilities in binary form, namely, "0" (combining "can do it with difficulty" and "unable to do it") and "1" (no difficulty or functional independence of a person). The scores for all three types of disability were then added to create the ' $\mathrm{Kz}$ score'. Finally, this combined score was split into three groups, namely, "Kz score $=3$ " (no difficulty in any ADL), "Kz score=1 or 2" (mild or severe disability in one or two ADLs), and "Kz score $=0$ " (mild or severe disability in all three ADLs). Thus, an elderly person with a $\mathrm{Kz}$ score of less than 3 was suffering from multiple disabilities at the time of the interview.

Secondly, we took each of the ADLs (walking, toileting and dressing) as dependent variables (categorized into "no difficulty," "can do with difficulty" and "unable to do it") to examine the role of morbidities according to type of disability.

\section{Exposure variables}

The main exposure variable in our analysis was the presence of any three types of chronic morbidities, specifically high blood pressure (high BP), heart disease and diabetes. The exact question was: "Has a doctor ever diagnosed any member in the household as having - high BP/heart disease/diabetes?"

Following the available literature, we included a set of demographic and socioeconomic variables in the regression model. These are: age (60-69, 70-79, 80-89); sex (male or female); place of residence (rural or urban); marital status (currently married, never married and other); religion (Hindu, Muslim and other), caste (scheduled caste, scheduled tribe and other), wealth index quintiles (Q1,
Q2, Q3, Q4, Q5); and level of education (no education, primary, secondary or higher).

To clarify the terminology of the variables above, we define caste as a 'social stratification' in the Hindu religion where there are four Varnas or tiers: Brahmin (priest and teacher), Kshatriya (ruler and warrior), Vaishya (trader), and Shudra (servant), which are further divided into smaller social groups. The dailts (untouchables) and adivasis (tribals) are considered to be outside of the caste system and are therefore seen as the lowest in the social hierarchy. They are referred to as scheduled caste (SC) and scheduled tribe (ST) respectively [40]. The constitution of India urges positive measures for the people belonging to the SC and ST community in order to uplift their socioeconomic status. The variable wealth quintile index, on the other hand, is generated by dividing the total household income given in the dataset of the IHDS (from agriculture, livestock, salaries, wages, non-farm business, property and other assets, pensions, scholarships and government benefits) into five equal parts namely, Q1, Q2, Q3, Q4 and Q5 in ascending order, thus representing the economic hierarchy.

\section{Statistical analysis}

First, we cross-tabulated the dependent and the independent variables to understand the distribution of the disability status across demographic and socioeconomic characteristics. Ordered logistic regression was carried out to examine the relationship between three types of morbidity and disability indices, based on three ADLs. In addition, ordered logistic regression was carried out to examine the relationship between three types of morbidity and each of the three types of ADLs listed above. To test the proportional odds assumption for ordinal logistic regression, the Brant Test was conducted. The proportional odds assumption, or the parallel odds assumption, states that each pair of response variables has the same relationship from the lowest through to the highest category, as described in the variable. A post-estimation test was also done to check the multi-collinearity between high BP, heart disease and diabetes. All the analyses were conducted on a population older than 60 years, using the STATA statistical software package version 14 .

\section{Results}

Prevalence of disability in three ADLs by gender

Table 1 presents Katz's score in ADL (expressed in \%) among the population aged 60 and above in India, 20112012. This table reveals many important findings about the status of disability among the elderly in India.

First, the percentage of people over 60 obtaining lower Katz scores (indicating either mild or severe disability) in any of the three ADLs is very high (17.93\% for men and $26.21 \%$ for women). For both genders, the Katz 
Table 1 Katz (Kz) score in ADL (expressed in \%) among population aged 60 and above in India, 2011-2012

\begin{tabular}{|c|c|c|c|c|c|c|}
\hline \multirow[t]{2}{*}{$\overline{A D L}$} & \multicolumn{3}{|l|}{ Male $(N=10,523)$} & \multicolumn{3}{|c|}{ Female $(N=11,402)$} \\
\hline & $\begin{array}{l}\text { Severe } \\
(\text { Kz score }=0) \%\end{array}$ & $\begin{array}{l}\text { Mild } \\
(\text { Kz score = 1) \% }\end{array}$ & $\begin{array}{l}\text { Non-disabled } \\
(\text { Kz score }=2) \%\end{array}$ & $\begin{array}{l}\text { Severe } \\
(\text { Kz score }=0) \%\end{array}$ & $\begin{array}{l}\text { Mild } \\
(\text { Kz score = 1) \% }\end{array}$ & $\begin{array}{l}\text { Non-disabled } \\
(\text { Kz score }=2) \%\end{array}$ \\
\hline Walking & 6.02 & 11.67 & 82.31 & 9.48 & 16.32 & 74.19 \\
\hline Toileting & 2.34 & 4.79 & 92.87 & 3.45 & 7.07 & 89.47 \\
\hline Dressing & 1.98 & 2.85 & 95.17 & 2.98 & 4.86 & 92.16 \\
\hline At least one of above & 6.66 & 11.27 & 82.07 & 10.51 & 15.7 & 73.79 \\
\hline
\end{tabular}

$\mathrm{Kz}$ score $=0$ : Unable to perform $\mathrm{ADL} ; \mathrm{Kz}$ score $=1$ : Can do with difficulty $\mathrm{ADL} ; \mathrm{Kz}$ score $=2$ : fully functional $\mathrm{ADL}$

score of mild disability in ADLs is much higher than that of severe disability. Second, irrespective of the type of $\mathrm{ADL}$ and the severity of the corresponding disability, the Katz scores for severe disability in ADLs are higher in elderly females than in elderly males. Finally, the Katz score of severe disability in walking for both genders is the highest (for Kz score = 0, 6.02\% for men vs $9.48 \%$ for women; for $\mathrm{Kz}$ score $=1,11.67 \%$ for men vs $16.32 \%$ for women). Disability in walking was followed by disability in toileting (for $\mathrm{Kz}$ score $=0$, 2.34\% for men vs 3.45\% for women, and for $\mathrm{Kz}$ score =1, 4.79\% for men vs $7.07 \%$ for women).

\section{Disability status by socioeconomic characteristics and type of morbidity}

Table 2 presents the disability prevalence expressed as Katz's scores in ADL (in \%) in the Indian population aged 60 and above by demographic and socioeconomic characteristics.

The most striking finding of Table 2 is that the lowest Katz score in ADLs $(\mathrm{Kz}=0)$, that is, disability in all three ADLs, is higher among people diagnosed with chronic morbidities. For instance, the prevalence rate of disability in elderly people with diabetes and high BP is double (for $\mathrm{Kz}$ score $<3$ ) than for elderly persons without these morbidities (diabetes: $10.34 \%$ vs. $5.45 \%$; high BP: $10.58 \%$ vs. $5.16 \%$ ).

In general, the percentage of women with Katz scores of higher disability in multiple ADLs is higher than that of men. Moreover, as age increases, the Katz score of disability in ADL also rises. There is a marginal difference in disability prevalence by type of residence and religion. The results also indicate that widows or divorcees (included in the "other" category in marital status) are at higher risk of suffering from disability than their married counterparts. Katz scores of higher disability in three ADLs $(\mathrm{Kz}$ score $=0)$ is more prevalent among older Muslims than among elderly people from other religions (Hindu: 5.71\%; Muslims: $6.82 \%$ and other: 5.02\%). The disability rate is lowest among older people belonging to the ST (4.11\%). No clear downward gradient between the disability rate and wealth index is observed, although the lowest Katz score in ADL $(\mathrm{Kz}$ score $=0)$ is observed among those in the lowest wealth quintile. Disability rates are reduced substantially from the uneducated to the higher-educated group (for $\mathrm{Kz}$ score $=0$, uneducated: $6.59 \%$, higher educated $2.95 \%$ ).

\section{Type of disability by chronic morbidities and socioeconomic characteristics}

Table 3 presents Katz scores in each ADL (expressed in \%) in the population aged 60 and above by socioeconomic characteristics. The Katz score of highest disability in ADLs $(\mathrm{Kz}$ score $<2)$ was found to be the highest among the elderly suffering from high BP. Walking-related disability was also prominent among the elderly with major morbidities like cardiovascular disease and diabetes. Among high BP patients, mild disability $(\mathrm{Kz}$ score $=1)$ in toileting and dressing is 11.37 and $7.21 \%$, respectively. About $24.55 \%$ of diabetes patients have mild walking-related disabilities $($ Kz score $=1)$.

Consistent with Table 2, females are found to bear an unequal burden of disability, most noticeably in walking (for $\mathrm{Kz}$ score $=1$, walking $=16.32 \%$, toileting $=7.07 \%$, and dressing $=4.86 \%$ ). Most of the disabled population come from the 60-64 age group, but the highest prevalence of disability is observed in the over- 80 age group. The ranking of disability prevalence for mild and severe disability for the over-80 population is as follows: walking (Kz score $=1: 23 \%, \mathrm{Kz}$ score $=0: 20 \%)$, toileting $(\mathrm{Kz}$ score $=1: 15 \%, \mathrm{Kz}$ score $=0: 8 \%)$ and dressing $(\mathrm{Kz}$ score $=1: 11 \%, \mathrm{Kz}$ score $=0: 7 \%)$. This ranking remained almost the same in all other socioeconomic subgroups. Mild disability is more prevalent than severe disability across all categories.

Another distinctive feature of Table 3 is that most of the elderly with mild or severe $(\mathrm{Kz}$ score $<2)$ disabilities belong to the poor wealth quintile and are illiterate. Progressing through the higher categories of each distinctive group of wealth quintile and education, one sees the situation improving a little. However, the highest wealth quintile is seen to report a high mild disability $(\mathrm{Kz}$ score $=1)$ prevalence for walking.

Disabilities of toileting and dressing-related ADLs are more prevalent among the Muslim than the Hindu population. People belonging to the STs have the least prevalence of disability, compared to those from the SC 
Table 2 Disability prevalence expressed as Katz score in ADL (in \%) in population aged 60 and above by demographic and socioeconomic characteristics, India, 2011-2012

\begin{tabular}{|c|c|c|c|c|}
\hline Characteristics & $\mathrm{N}$ & Kz score $=0$ & Kz score $=1$ or 2 & Kz score $=3$ \\
\hline \multicolumn{5}{|l|}{ Chronic morbidity } \\
\hline \multicolumn{5}{|l|}{ High BP } \\
\hline No & 19,421 & 5.16 & 15.08 & 79.77 \\
\hline Yes & 2504 & 10.58 & 26.8 & 62.62 \\
\hline \multicolumn{5}{|l|}{ Heart diseases } \\
\hline No & 21,318 & 5.68 & 16.13 & 78.19 \\
\hline Yes & 607 & 9.03 & 26.46 & 64.51 \\
\hline \multicolumn{5}{|l|}{ Diabetes } \\
\hline No & 20,467 & 5.45 & 15.77 & 78.78 \\
\hline Yes & 1458 & 10.34 & 25.47 & 64.18 \\
\hline \multicolumn{5}{|l|}{ Sex } \\
\hline Male & 10,636 & 4.43 & 13.5 & 82.07 \\
\hline Female & 11,289 & 7.04 & 19.16 & 73.79 \\
\hline \multicolumn{5}{|l|}{ Age } \\
\hline $60-64$ & 7389 & 2.40 & 10.62 & 86.98 \\
\hline $65-69$ & 5802 & 3.71 & 14.55 & 81.74 \\
\hline $70-74$ & 3916 & 6.20 & 19.35 & 74.44 \\
\hline $75-79$ & 2254 & 8.21 & 23 & 68.8 \\
\hline $80+$ & 2563 & 17.37 & 27.11 & 55.51 \\
\hline \multicolumn{5}{|l|}{ Place of residence } \\
\hline Rural & 15,442 & 5.71 & 16.98 & 77.31 \\
\hline Urban & 6483 & 5.92 & 15.09 & 79 \\
\hline \multicolumn{5}{|l|}{ Marital status } \\
\hline Currently married & 13,213 & 3.77 & 13.43 & 82.81 \\
\hline Never married & 222 & 4.71 & 18.53 & 76.76 \\
\hline Other & 8490 & 8.93 & 21.02 & 70.05 \\
\hline \multicolumn{5}{|l|}{ Religion } \\
\hline Hindu & 18,410 & 5.71 & 16.52 & 77.77 \\
\hline Muslim & 2133 & 6.82 & 14.69 & 78.49 \\
\hline Other & 1382 & 5.02 & 17.77 & 77.21 \\
\hline \multicolumn{5}{|l|}{ Caste } \\
\hline SC & 4238 & 5.65 & 16.17 & 78.18 \\
\hline ST & 1400 & 4.11 & 11.36 & 84.53 \\
\hline Other & 16,227 & 5.95 & 16.93 & 77.12 \\
\hline \multicolumn{5}{|l|}{ Wealth } \\
\hline Q1 & 6301 & 6.17 & 18.66 & 75.17 \\
\hline Q2 & 4088 & 6.68 & 14.91 & 78.41 \\
\hline Q3 & 3755 & 5.58 & 16.76 & 77.66 \\
\hline Q4 & 3977 & 5.06 & 14.71 & 80.22 \\
\hline Q5 & 3804 & 5.09 & 15.77 & 79.14 \\
\hline
\end{tabular}


Table 2 Disability prevalence expressed as Katz score in ADL (in \%) in population aged 60 and above by demographic and socioeconomic characteristics, India, 2011-2012 (Continued)

\begin{tabular}{lllll}
\hline Characteristics & $\mathrm{N}$ & Kz score $=0$ & Kz score $=1$ or 2 & Kz score $=3$ \\
\hline Education & & & & 18 \\
No education & 12,921 & 6.59 & 16.14 & 75.41 \\
Primary & 3829 & 5.31 & 13.32 & 78.55 \\
Secondary & 3683 & 4.56 & 10.66 & 82.12 \\
Higher & 1449 & 2.95 & 16.88 & 86.39 \\
Total & 21,926 & 5.45 & 77.67 \\
\hline
\end{tabular}

Disability prevalence is measured by Katz score (Kz score) which is constructed using the Katz Index of Independence in ADL with three categories, specifically: Disability in three ADLs: Kz score =0; Disability in 1 or 2 ADLs: Kz score $=1$ or 2; Fully functional ADL: Kz score $=3$. Functional independence increases with higher Kz score

and other castes. Clearly visible for SC, ST and other castes, for example, is the difference in the prevalence of severe disability $(\mathrm{Kz}$ score $=0)$ in walking (SC: $8.74 \%$, ST: $5 \%$ and other: $7.79 \%)$ and mild disability (Kz score $=1$ ) for dressing (SC: 3.5\%, ST: 1.95\% and other: 4.14\%).

\section{Role of morbidity on disability: Results of regression analysis}

Table 4 shows the results of the ordered logistic regression revealing the role of chronic morbidity in disability in ADLs.

It is clear from Table 4 that almost all chronic morbidities have a statistically significant relationship with disability conditions in ADLs. Elderly people suffering from any type of chronic morbidity have at least a 1.8 times greater chance of having a disability condition, than those not suffering from any chronic morbidity. Elderly people suffering from diabetes (odds ratio (OR): 2.03, 95\% confidence interval (CI): $1.80-2.29 \%$ ) were more likely to report disability, compared to adults suffering from heart disease (OR: 1.8, 95\% CI: 1.52-2.13) and high BP (OR: 1.94, 95\% CI: 1.76-2.13). Overall, the proportion of elderly people with a higher level of education and income reported old age disability the least. Compared to currently married elderly persons, the divorced/ separated elderly (counted in the 'other' category) report a higher incidence of disability (OR: 1.27, 95\% CI: 1.171.37).

Table 5 presents the ordered logistic regression results of three different types of disability. All the models are adjusted for gender, age, education, wealth quintile, caste, religion and place of residence. It confirms that all the listed morbidities have a significant effect on a specific type of ADL. Diabetes appeared as the biggest threat to walking (OR: 2.56; 95\% CI: 2.29-2.86), toileting (OR: 2.63; 95\% CI: 2.26-3.07) and dressing- (OR: 2.5; 95\% CI: 2.09-2.99). High BP mainly affects walking (OR: 2.29; 95\% CI: 2.09-2.5) and dressing disabilities (OR: 2.13; 95\% CI: 1.84-2.46).

Heart disease least affects dressing-related disability as compared to high BP and diabetes.

\section{Discussion}

As a result of increased population aging, the importance of disability studies among the elderly in India has been increasing for decades. The aim of this study has been to examine the nature and magnitude of the association between chronic morbidities and disability among the elderly in the country, using recently available nationally representative data. Unlike previous studies focusing on a specific disability, we documented the association between a set of major morbidities and disability conditions across three ADLs.

One important finding of this study is that the burden of disability among the elderly is enormous in India. Our study shows that about $17.93 \%$ of elderly men and $26.21 \%$ of elderly women in the country experience either mild or severe disability in three ADLs needed for a better quality of life. This indicates that about 9 million elderly men and 14 million elderly women in India have at least one type of disability, according to IHDS data. The ADL-based disability estimates presented in the current study is far higher than the disability estimates in the Indian census [1].

Our study demonstrates that disability prevalence is higher among women, those not currently married, and the oldest of the elderly (above 80 years). Wealthy elderly people experience a lower prevalence of disability than the poor do. The odds of experiencing disability decreases as level of education increases. Contrary to previous findings [1], disability prevalence is lower among the ST population. This may be the result of under-reporting, as self-reported health or disability, being a subjective measure, may depend on the level of awareness about health or disability. This needs further detailed investigation.

In accordance with previous research, our study also confirms that there is a strong positive association between the existence of any morbidity and any disability in ADLs [3, 41, 42]. One of the major findings of our study is that diabetes causes the highest likelihood of any disability among the elderly, followed by high BP and heart disease. Another major finding of our study is that we were able to quantify the relative role of morbidities for each specific disability. For instance, according 


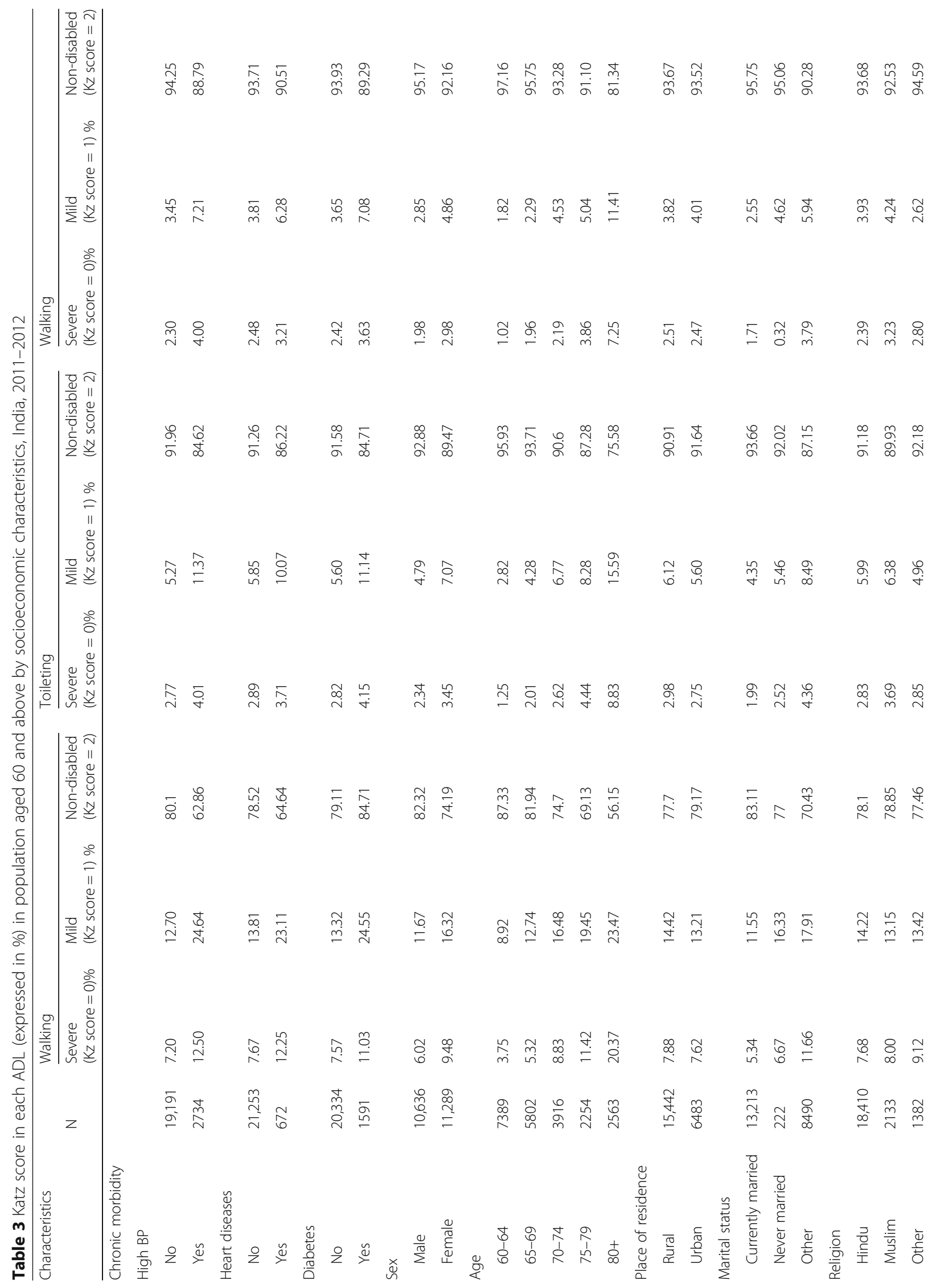




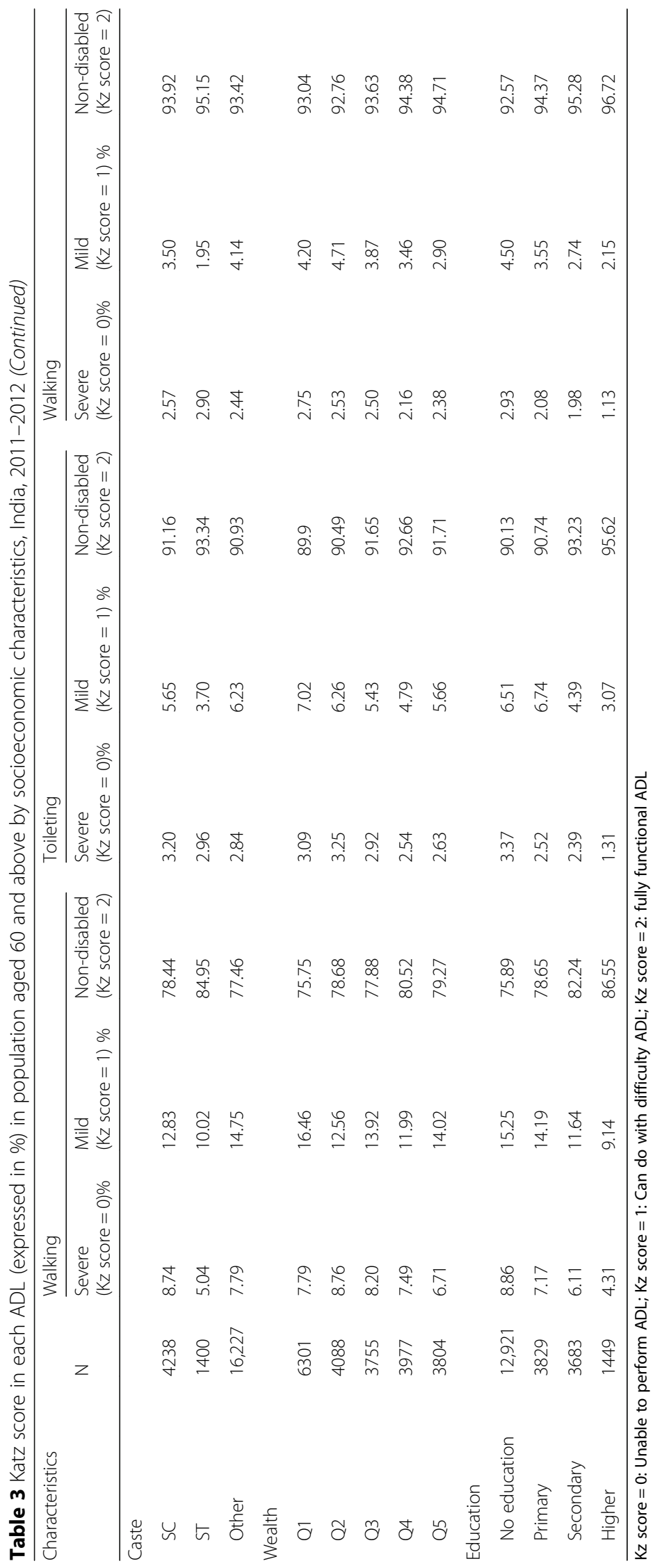


Table 4 Ordered logistic regression analysis of disability prevalence among population aged 60+ in India, 2011-2012

\begin{tabular}{|c|c|c|c|c|}
\hline \multirow[t]{2}{*}{ Background variable } & \multirow{2}{*}{$\begin{array}{l}\text { Odds } \\
\text { ratio }\end{array}$} & \multirow[t]{2}{*}{$p$-value } & \multicolumn{2}{|c|}{$95 \%$ Confidence interval } \\
\hline & & & Lower & Upper \\
\hline \multicolumn{5}{|l|}{ Chronic morbidity } \\
\hline High BP ( $\left.\mathrm{No}^{\mathrm{a}}, \mathrm{Yes}\right)$ & 1.94 & $p<0.0001$ & 1.76 & 2.13 \\
\hline Heart diseases (No ${ }^{a}$, Yes) & 1.80 & $p<0.0001$ & 1.52 & 2.13 \\
\hline Diabetes ( $\left.\mathrm{No}^{\mathrm{a}}, \mathrm{Yes}\right)$ & 2.03 & $p<0.0001$ & 1.80 & 2.29 \\
\hline \multicolumn{5}{|l|}{ Sex } \\
\hline \multicolumn{5}{|l|}{ Male $^{a}$} \\
\hline Female & 1.35 & $p<0.0001$ & 1.25 & 1.46 \\
\hline Age & 1.07 & $p<0.0001$ & 1.07 & 1.08 \\
\hline \multicolumn{5}{|l|}{ Education } \\
\hline \multicolumn{5}{|l|}{ Illiterate ${ }^{a}$} \\
\hline Primary & 0.99 & 0.8060 & 0.90 & 1.09 \\
\hline Secondary & 0.85 & 0.0050 & 0.77 & 0.95 \\
\hline Higher & 0.68 & $p<0.0001$ & 0.57 & 0.81 \\
\hline \multicolumn{5}{|l|}{ Wealth } \\
\hline \multicolumn{5}{|l|}{ Poorest ${ }^{a}$} \\
\hline Poor & 0.80 & $p<0.0001$ & 0.72 & 0.88 \\
\hline Middle & 0.85 & 0.0020 & 0.77 & 0.95 \\
\hline Rich & 0.70 & $p<0.0001$ & 0.64 & 0.78 \\
\hline Richest & 0.66 & $p<0.0001$ & 0.60 & 0.74 \\
\hline \multicolumn{5}{|l|}{ Religion } \\
\hline \multicolumn{5}{|l|}{$\mathrm{Hindu}^{a}$} \\
\hline Muslim & 1.01 & 0.8550 & 0.90 & 1.13 \\
\hline Other & 1.00 & 0.9520 & 0.87 & 1.13 \\
\hline \multicolumn{5}{|l|}{ Caste } \\
\hline \multicolumn{5}{|l|}{$\mathrm{SC}^{\mathrm{a}}$} \\
\hline ST & 0.83 & 0.0200 & 0.70 & 0.97 \\
\hline Other & 1.05 & 0.3290 & 0.96 & 1.14 \\
\hline \multicolumn{5}{|l|}{ Residence } \\
\hline \multicolumn{5}{|l|}{ Urban $^{a}$} \\
\hline Rural & 0.89 & 0.0030 & 0.82 & 0.96 \\
\hline \multicolumn{5}{|l|}{ Marital status } \\
\hline \multicolumn{5}{|l|}{ Currently married ${ }^{a}$} \\
\hline Never married & 1.08 & 0.6790 & 0.76 & 1.52 \\
\hline Other & 1.27 & $p<0.0001$ & 1.17 & 1.37 \\
\hline
\end{tabular}

Dependent variable: Disability index with three categories viz. No ADL, 1-2 ADL, > = 3 ADL

${ }^{\mathrm{a}}$ Reference category

to our study, the likelihood of disability is always the highest among diabetes patients, whereas the disability rate is the lowest among elderly persons with heart disease. This may be due to mortality selection among heart patients. It is found that heart disease is the topmost cause of death in India, whereas diabetes is the seventh most common cause of death [42]. Previous studies show heart disease and diabetes as a major contributing factor in disability [43] but this study gives relative role of heart disease and diabetes in the disablement process. These results are helpful for both patients and healthcare providers in terms of taking preventive measures at the onset of morbidities.

The strength of our study is the fact that we use information from recently available population based survey data. This helps to give a clear picture about the level of 
Table 5 Ordered logistic regression analysis of specific disability prevalence among population aged 60+ in India, 2011-2012

\begin{tabular}{|c|c|c|c|c|c|c|}
\hline & \multirow{2}{*}{$\begin{array}{l}\text { Dependent } \\
\text { variable }\end{array}$} & \multirow{2}{*}{$\begin{array}{l}\text { Independent } \\
\text { variable }\end{array}$} & \multirow{2}{*}{$\begin{array}{l}\text { Odds } \\
\text { ratio }\end{array}$} & \multirow[t]{2}{*}{$p$-value } & \multicolumn{2}{|c|}{ 95\% Confidence interval } \\
\hline & & & & & Lower & Upper \\
\hline \multirow[t]{3}{*}{ Model 1} & \multirow[t]{3}{*}{ Walking } & High BP & 2.29 & $p<0.0001$ & 2.09 & 2.50 \\
\hline & & Heart diseases & 2.31 & $p<0.0001$ & 1.96 & 2.71 \\
\hline & & Diabetes & 2.56 & $p<0.0001$ & 2.29 & 2.86 \\
\hline \multirow[t]{3}{*}{ Model 2} & \multirow[t]{3}{*}{ Toileting } & High BP & 2.10 & $p<0.0001$ & 1.85 & 2.39 \\
\hline & & Heart diseases & 2.06 & $p<0.0001$ & 1.64 & 2.58 \\
\hline & & Diabetes & 2.63 & $p<0.0001$ & 2.26 & 3.07 \\
\hline \multirow[t]{3}{*}{ Model 3} & \multirow[t]{3}{*}{ Dressing } & High BP & 2.13 & $p<0.0001$ & 1.84 & 2.46 \\
\hline & & Heart diseases & 1.99 & $p<0.0001$ & 1.54 & 2.59 \\
\hline & & Diabetes & 2.50 & $p<0.0001$ & 2.09 & 2.99 \\
\hline
\end{tabular}

Each model in the above table is adjusted for sex, age, education, wealth, religion, caste, residence and marital status

disability prevalence and disparities at the national level. To our knowledge, this is the first systematic study to analyse the association between various morbidities and disability conditions among the elderly at the national level in the country. Thus, our study is an important contribution to the understanding of disability conditions in India, which is one of the fastest aging countries in the world.

There are certain limitations to the current study. First, the IHDS data provides information on the disability conditions of the elderly, as reported by women (aged 15-49) in households matching the study criteria. Disability information from proxy respondents may be a limitation of this study. The literature suggests that in some cases, self-reporting and proxy reporting were correlated, while in other cases there were discrepancies regarding the disability condition of the elderly [44]. Yet, the direction of reporting (either under-reporting or over-reporting) by proxy respondents is not very conclusive in the relevant literature [45]. We therefore minimized the bias caused by proxy reporting by constructing a disability index.

Second, due to the small sample size, we could not encompass the individual influence of some of the major diseases such as sexually transmitted diseases (STDs) and AIDS, polio, cancer, leprosy, etc., on disability. It would have been preferable for the sample size to be large enough to analyse each disease and ADL separately.

\section{Conclusions}

This study reveals that the burden of disability among the elderly in India is enormous and there is a strong relation between chronic morbidity and disability in them. More specifically, diabetes is an important contributing factor to disability than heart diseases. This burden may increase in the near future if public-health policies are not formulated and executed in a timely fashion. The burden of unhealthy aging can be a serious threat to sustainable economic development in the country. To address the present condition, it is important to expand societal and institutional support to the disabled elderly. Healthcare, transport, and other community-level facilities should be conducive to helping disabled elderly persons live out their lives with dignity. Due to the changing family system and related values, the elderly, particularly the disabled elderly, are susceptible to various kinds of abuse. Government assistance to families with disabled elderly members is thus much needed.

At the same time, an environment to prepare adults for healthy aging is the message of the moment. As morbidity is a major risk factor influencing disability in the elderly, a social environment should be created for early detection and postponing the onset of morbidity as the later stages of life approaches, by focusing on a healthy lifestyle from the beginning of adulthood. To achieve this, all stakeholders including government, community health workers, and civil society, need to play an essential role.

\section{Abbreviations \\ ADL: Activities of daily living; BP: Blood pressure; IHDS: India Human Development Survey; NCAER: National Council of Applied Economic Research; OR: Odds ratio; SC: Scheduled caste; ST: Scheduled tribe}

\section{Acknowledgements \\ Not applicable}

Funding

The authors declare that no funding of any kind was granted for this study.

\section{Availability of data and materials}

We used publicly available secondary survey data obtained from the India Human Development Survey-II (IHDS-II). The IHDS-II data supporting the findings of this study is available in the public domain for download in the IHDS repository, (https://doi.org/10.3886/ICPSR36151.v5) [38]. The IHDS followed ethical clearance guidelines and norms. Before their interviews, all respondents signed a "consent statement". This provided them with the option to decline to answer any question and noted specifically that the data collected would be used solely for the purpose of research and, moreover, that the confidentiality of personal details would not be jeopardized [38]. No separate ethics statement and consent for publication was required for this study. 


\section{Authors' contributions}

The authors contributed equally to this work. MCP and NS participated equally in the conceptualisation, design and analysis of this paper. MCP drafted the article. NS revised the content of the paper critically for important intellectual content and approved the submitted version. All authors read and approved the final manuscript.

Ethics approval and consent to participate

Not applicable

\section{Consent for publication}

Not applicable

\section{Competing interests}

The authors declare that they have no competing interests.

\section{Publisher's Note}

Springer Nature remains neutral with regard to jurisdictional claims in published maps and institutional affiliations.

\section{Author details}

${ }^{1}$ Centre for the Study of Regional Development, School of Social Sciences, Jawaharlal Nehru University, New Delhi, India. ${ }^{2}$ International Institute for Applied Systems Analysis, Laxenburg, Austria.

Received: 12 May 2018 Accepted: 13 November 2018

Published online: 07 December 2018

\section{References}

1. Saikia N, Bora JK, Jasilionis D, Shkolnikov VM. Disability Divides in India: Evidence from the 2011 Census. Kokubo Y, editor. PLoS One. 2016;11: e0159809.

2. Velayutham B, Kangusamy B, Joshua V, Mehendale S. The prevalence of disability in elderly in India-analysis of 2011 census data. Disabil Health J. 2016:9(4):584-92.

3. Fried LP, Bandeen-Roche K, Kasper JD, Guralnik JM. Association of Comorbidity with disability in older women: the Women's health and aging study. J Clin Epidemiol. 1999;52:27-37.

4. Martin LG, Schoeni RF. Trends in disability and related chronic conditions among the forty-and-over population: 1997-2010. Disabil Health J. 2014;7: S4-S14.

5. Costa DL. Changing chronic disease rates and long-term declines in functional limitation among older men. Demography. 2002;39:119-37.

6. Freedman VA, Martin LG. Contribution of chronic conditions to aggregate changes in old-age functioning. Am J Public Health. 2000;90:1755.

7. Liang J, Liu X, Gu S. Transitions in functional status among older people in Wuhan, China: Socioeconomic differentials. J Clin Epidemiol. 2001;54:1126-38.

8. Tey NP, Lai SL, Teh JK. The debilitating effects of chronic diseases among the oldest old in China. Maturitas. 2016;94:39-45.

9. Lin S-F, Beck AN, Finch BK. The dynamic contribution of chronic conditions to temporal trends in disability among US adults. Disabil Health J. 2016;9: 332-40.

10. Martin LG, Freedman VA, Schoeni RF, Andreski PM. Trends in disability and related chronic conditions among people ages fifty to sixty-four. Health Aff. 2010;29:725-31.

11. Freedman VA, Crimmins EM, Schoeni RF, Spillman BC, Aykan H, Kramarow E, et al. Resolving inconsistencies in trends in old-age disability: report from a technical working group. Demography. 2004;41:417-41 Springer-Verlag.

12. Schmitz N, Wang J, Malla A, Lesage A. Joint effect of depression and chronic conditions on disability: results from a population-based study. Psychosom Med. 2007;69:332-8.

13. Schmitz N, Gariépy G, Smith KJ, Clyde M, Malla A, Boyer R, et al. Recurrent subthreshold depression in type 2 diabetes: an important risk factor for poor health outcomes. Diabetes Care. 2014;37:970-8.

14. Deschênes SS, Burns RJ, Schmitz N. Associations between depression, chronic physical health conditions, and disability in a community sample: a focus on the persistence of depression. J Affect Disord. 2015;179:6-13.

15. Rijken M, van Kerkhof M, Dekker J, Schellevis FG. Comorbidity of chronic diseases. Qual Life Res. 2005;14:45-55.
16. Gijsen R, Hoeymans N, Schellevis FG, Ruwaard D, Satariano WA, van den Bos GA. Causes and consequences of comorbidity: a review. J Clin Epidemiol. 2001;54:661-74.

17. Jeffery R, Singal N. Measuring disability in India. Econ Polit Wkly. 2008:43(12/ 13):22-24.

18. Mitra S, Sambamoorthi U. Disability estimates in India: what the census and NSS tell us. Econ Polit Wkly. 2006;41(38):4022-26.

19. Addlakha R, Mandal S. Disability law in India: paradigm shift or evolving discourse? Econ Polit Wkly. 2009;44(41/42):62-68.

20. Filmer D. Disability, poverty, and schooling in developing countries: results from 14 household surveys. World Bank Econ Rev. 2008;22:141-63.

21. Das D, Agnihotri SB. Physical disability- is there a gender dimension? Econ Polit Wkly. 1998;33(52):3333-35.

22. Singh A. Burden of disability in a Chandigarh village. Indian J Community Med. 2008;33:113.

23. Salomon JA, Wang H, Freeman MK, Vos T, Flaxman AD, Lopez AD, et al. Healthy life expectancy for 187 countries, 1990-2010: a systematic analysis for the global burden disease study 2010. Lancet. 2013;380:2144-62.

24. Joshi K, Kumar R, Avasthi A. Morbidity profile and its relationship with disability and psychological distress among elderly people in northern India. Int J Epidemiol. 2003:32:978-87 Oxford University Press.

25. Bose A. Increasing life expectancy and the elderly. Econ Polit Wkly. 2008; 43(32):41-42.

26. Pandey MK. Poverty and disability among elderly in India: evidences from household survey[Internet]. 2009 Jun [cited 2018 Nov 7]. Available from: https://mpra.ub.uni-muenchen.de/15930/.

27. Lau RS, Johnson S, Kamalanabhan TJ. Healthy life expectancy in the context of population health and ageing in India. Asia-Pacific J Public Heal. 2012;24: 195-207.

28. Thomas M, Benson K, James S, Sulaja S. Does living longer mean living healthier? Exploring disability free life expectancy in India. Indian J Gerontol. 2014:28:321-47.

29. Mishra AK, Gupta R. Disability index: a measure of deprivation among disabled. Econ Polit Wkly. 2006;41(38):4026-29.

30. Bora JK, Saikia N. Gender Differentials in Self-Rated Health and Self-Reported Disability among Adults in India. Moore S, editor. PLoS One. 2015;10: e0141953 Public Library of Science.

31. Crimmins E, Saito Y. Change in the prevalence of diseases among older Americans: 1984-1994. Demogr Res [Internet]. 2000;3(9) [cited 2018 Nov 7] Available from: www.demographic-research.org/Nolumes/Nol3/9/. https:// doi.org/10.4054/DemRes.2000.3.9.

32. Bhattacharya J, Choudhry K, Lakdawalla D. Chronic disease and severe disability among working-age populations. Med Care. 2008;46:92-100.

33. Ross CE, Wu C. The links between education and health. Am Sociol Rev. 1995;60(5):719-45

34. Schoeni RF, Martin LG, Andreski P, Freedman VA. Growing disparities in trends in old-age disability 1982-2001. Am J Public Health. 2005;95:2065-70.

35. Shivakumar P, Sadanand S, Bharath S, Girish N, Varghese M. Identifying psychological distress in elderly seeking health care. Indian J Public Health. 2015;59:18.

36. Bandhu SD, Vabale YG, Sambarey PP, Walke AB, Raje S. Impact of cataract on the quality of life of rural patients in India. J Clin Ophthalmol Res. 2016:4:75.

37. Patel V, Pereira J, Coutinho L, Fernandes R, Fernandes J, Mann A. Poverty, psychological disorder and disability in primary care attenders in Goa, India. Br J Psychiatry. 1998;172:533-6.

38. Desai S, Vanneman R. India Human Development Survey-II (IHDS-II), 2011 12. Ann Arbor, MI: Inter-university Consortium for Political and Social Research [distributor]. 2017. https://doi.org/10.3886/ICPSR36151.v5. Accessed 13 Oct 2017.

39. Brorsson B, Asberg KH. Katz index of independence in ADL. Reliability and validity in short-term care. Scand J Rehabil Med. 1984;16:125-32.

40. Desai S, Kulkarni V. Changing educational inequalities in India in the context of affirmative action. Demography. 2008 May 1;45(2):245-70.

41. Verbrugge LM, Lepkowski JM, Imanaka Y. Comorbidity and Its Impact on Disability. Milbank Q. 1989;67:450 WileyMilbank Memorial Fund.

42. Indian Council of Medical Research, Public Health Foundation of India, and Institute for Health Metrics and Evaluation. Health of the nation's states the India state-level disease burden initiative [Internet]. New Delhi (IN): ICMR, PHFI, and IHME; 2017 Dec [cited 2018 Nov 7]. 211 pg. Available from: http://www.healthdata.org/sites/default/files/files/2017 India_State-Level Disease_Burden_Initiative_-_Full_Report\%5B1\%5D.pdf. 
43. Yokota RT, Van der Heyden J, Nusselder WJ, Robine J-M, Tafforeau J, Deboosere P, et al. Impact of Chronic Conditions and Multimorbidity on the Disability Burden in the Older Population in Belgium. Journals Gerontol Ser A. 2016;71:903-9.

44. Epstein AM, Hall JA, Tognetti J, Son LH, Conant L Jr. Using proxies to evaluate quality of life: can they provide valid information about patients' health status and satisfaction with medical care? Med Care. 1989;27:S91-8.

45. Todorov A, Kirchner C. Bias in proxies' reports of disability: data from the National Health Interview Survey on disability. Am J Public Health. 2000;90:1248.

Ready to submit your research? Choose BMC and benefit from:

- fast, convenient online submission

- thorough peer review by experienced researchers in your field

- rapid publication on acceptance

- support for research data, including large and complex data types

- gold Open Access which fosters wider collaboration and increased citations

- maximum visibility for your research: over $100 \mathrm{M}$ website views per year

At $\mathrm{BMC}$, research is always in progress.

Learn more biomedcentral.com/submissions 